\title{
Vaginal Revision of a Haematoma after Placement of Retropubic Tapes in Two Cases
}

\author{
Vaginale Revision eines Hämatoms nach retropubischer \\ Bandeinlage in zwei Fällen
}

Authors

Affiliation
S. Harf, J. Marschke, A. Lippkowski, K. Beilecke, R. Tunn

Deutsches Beckenbodenzentrum, Fachbereich Urogynäkologie, St. Hedwig Kliniken Berlin, Berlin

\section{Key words}

- retropubic haematoma

- vaginal revision

- retropubic tape placement

Schlüsselwörter

- retropubisches Hämatom

- vaginale Revision

- retropubische Bandeinlage

Deutschsprachige Zusatzinformationen online abrufbar unter: www.thieme-connect.de/ ejournals/toc/gebfra

$\begin{array}{ll}\text { received } & 19.11 .2014 \\ \text { revised } & 22.12 .2014 \\ \text { accepted } & 5.1 .2015\end{array}$

Bibliography

DoI http://dx.doi.org/ 10.1055/s-0035-1545818

Geburtsh Frauenheilk 2015; 75 : 255-258 @ Georg Thieme

Verlag KG Stuttgart · New York . ISSN 0016-5751

\section{Correspondence}

Sina Harf

St. Hedwig Kliniken Berlin Deutsches Beckenbodenzentrum

Fachbereich Urogynäkologie Große Hamburger Straße 5-11

10115 Berlin

S.Harf@alexius.de

\section{Abstract \\ $\nabla$}

Formation of a haematoma after placement of retropubic tapes for stress incontinence is a rare but typical complication potentially requiring a subsequent operation. Under certain circumstances, haematoma removal by a vaginal approach represents a milder alternative to the subperitoneal laparotomy approach under general anaesthesia. We present two cases of vaginal haematoma revision after placement of retropubic tapes. By means of this gentle alternative to the standard laparotomy approach we could avoid general anaesthesia in one case and perform the operation under analgosedative local anaesthesia. In the second case, use of the vaginal approach enabled us to avoid a laparotomy in this obese patient with a superinfected haematoma that could have led to a possible secondary wound healing problem.

\section{Introduction \\ $\nabla$}

The retropubic placement of tension-free suburethral tapes belongs to the standard surgical therapy for stress incontinence [1,2]. Among the possible complications, besides the danger of intraoperative perforation of the urinary bladder, is the postoperative formation of a retropubic haematoma [3]. During movement of the special needle for inserting the tape along the rear edge of the symphysis through the lesser pelvis in a suprasymphysary direction, injuries to vessels in the retropubic space (cavum retzii) are possible and these can then lead to the formation of a retropubic haematoma. Haemorrhagic complications and haematoma formation are rare occurrences with an incidence of $2-3 \%$ but have been described $[3,4]$. In most cases a conservative wait and see procedure is possible. Kuuva et al. re-

\section{Zusammenfassung \\ $\nabla$}

Eine Hämatombildung nach retropubischer Bandeinlage bei Belastungsharninkontinenz ist eine seltene, aber typische und potenziell mit einem Folgeeingriff verbundene Komplikation. Unter bestimmten Bedingungen stellt die Hämatomausräumung von vaginal eine schonende Alternative zum laparotomisch subperitonealen Zugang in Vollnarkose dar. Vorgestellt werden 2 Fälle einer vaginalen Hämatomrevision nach retropubischer Bandeinlage. Durch diese schonende Alternative zum laparotomischen Standardzugang konnte in einem Fall eine Vollnarkose vermieden und der Eingriff in analgosedierter Lokalanästhesie durchgeführt werden. Im 2. Fall konnte durch den vaginalen Zugang die Durchführung einer Laparotomie, die im Falle einer adipösen Patientin mit superinfiziertem Hämatom eine mögliche sekundäre Wundheilung nach sich ziehen würde, vermieden werden.

ported on two revision operations in 27 cases of retropubic haematoma formation in Finland [3]. The rate of revisions in the Austrian registry of Kölle et al. amounts to $0.8 \%$ [4]. In the case of a revision operation to remove a symptomatic haematoma after retropubic tape placement, the laparotomy subperitoneal approach under general anaesthesia is the standard procedure, however, under certain circumstances the less traumatic vaginal approach under analgosedative local anaesthesia is also possible. We now report on two cases in which retropubic haematomas could successfully be removed by the vaginal approach. In one case the procedure was performed under analgosedative local anaesthesia; the vaginal approach thus represents a more gentle alternative under certain circumstances. 


\section{Case Reports}

$\nabla$

We report on two cases of vaginal revision of haematomas after retropubic placement of tapes, in the first case on the second postoperative day under analgosedative local anaesthesia and after 14 days under general anaesthesia in the second case.

\section{Case 1}

In the case of an 80-year-old patient without prior urogynaecological operations, a retropubic tape was inserted for clinically and urodynamically confirmed stress incontinence. After comprehensive information and consent by the patient the operation was performed successfully. During a routine follow-up examination (vaginal palpation and transvaginal ultrasound) on the 2nd postoperative day an 8 -cm diameter retropubic haematoma was detected by ultrasonography together with correct tape placement ( Fig. 1). The revision operation for removal of the haematoma was performed on the following day since the patient was haemodynamically stable and more or less free of pain. Because of a report of postoperative bleeding in the case history, we decided in favour of a vaginal revision under local anaesthesia, in order to minimise the renewed risk of bleeding due to an additional surgical approach and to avoid a second general anaesthesia. After performance of the revision operation without any complications, we decided to administer two erythrocyte concentrates in view of the patient's reduced general condition and initial postoperative anaemia (haemoglobin $5.10 \mathrm{mmol} / \mathrm{l}$ ). In the follow-up examination after haematoma removal we found a residual haematoma of ca. $4 \mathrm{~cm}$. Following mobilisation, an adequate increase of haemoglobin $(8.07 \mathrm{mmol} / \mathrm{l})$ and continuing antibiotic therapy the patient's general condition improved rapidly such that she could be released home in good general condition 3 days after the revision operation. In the course of the regular follow-up examination 2 months postoperatively, the patient presented in good health with a good bladder function.

\section{Case 2}

In the second case of a 75-year-old, obese (BMI $33.4 \mathrm{~kg} / \mathrm{m}^{2}$ ) patient with prior urogynaecological operations and mixed urinary incontinence with a urodynamically confirmed hypotonic urethra we also decided in favour of placement of a retropubic tape. Due to her condition after several operations for descensus and the preoperative sonographic suspicion of the suburethral presence of an inserted mesh (after cystocele correction with anterior mesh insertion), it was decided initially to remove part of this mesh in the course of the planned retropubic tape placement in order not only to make the topographically correct positioning of the retropubic tape possible, but also because we suspected that the false position of this mesh could be the cause of the urge components reported by the patient. After comprehensive clarification and the patient's informed consent, the operation was performed without any complications. In the immediate postoperative period the patient exhibited strongly hypertonic blood pressure values and the complaints of angina pectoris from the known arterial hypertension. After excluding an acute coronary syndrome, the patient spent the first postoperative night under observation in the intensive care unit.

Already on the 1st postoperative day, the patient's general condition was so good that she could be transferred to the normal ward. The further postoperative course was unremarkable. During a routine follow-up examination on the 2 nd postoperative day, a $6 \mathrm{~cm}$ diameter retropubic haematoma and correct tape po-

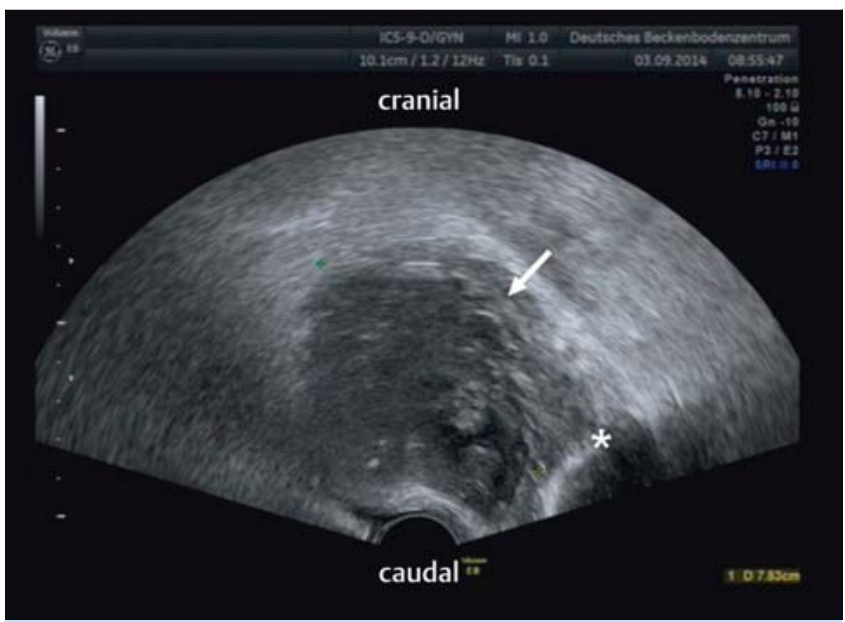

Fig. 1 Postoperative transvaginal ultrasonographic control after primary intervention in the 1st case with demonstration of a retropubic haematoma $($ ca. $8 \mathrm{~cm}) .{ }^{*}=$ symphysis.

sition were demonstrated by sonography. In consultation with the patient and in view of the almost complete freedom from pain, cardiovascular stability, residual urine-free spontaneous micturition and under consideration of the immediately postoperative hypertonic crisis, we decided in favour of conservative therapy. The patient was released home in good general condition on the 3rd postoperative day.

Fourteen days later the patient presented again in our urogynaecological office with a reduced general condition. Although she was still more or less free of pain the vaginal ultrasonographic examination revealed the already detected $6 \mathrm{~cm}$ diameter haematoma in a left paravesical position with correct tape position, however, on account of the obesity, the haematoma could be only poorly evaluated in the cranial direction. In view of the pathological laboratory values and highly elevated inflammatory parameters (haemoglobin $6.33 \mathrm{mmol} / \mathrm{l}$, thrombocytes $392 \mathrm{gpt} / \mathrm{l}$, leukocytes $10.7 \mathrm{gpt} / \mathrm{l}, \quad$-reactive protein $237.3 \mathrm{mg} / \mathrm{l}$; temperature $38.3^{\circ} \mathrm{C}$ ) the patient was admitted to our hospital and an intravenous antibiotic therapy with cefuroxim $3 \times 1.5 \mathrm{~g}$ and metronidazole $2 \times 500 \mathrm{mg}$ was initiated. Since the findings could not be completely evaluated by sonography, further imaging diagnostics were undertaken. After computed tomographic demonstration of a 600-700 $\mathrm{ml}$ haemorrhagic superinfected haematoma in the lesser pelvis we decided to remove the haematoma on the same day ( Fig. 2 a and b). Since, in view of the time point of the revision operation, a well advanced vaginal wound healing could be assumed, we also discussed an abdominal approach with the patient. The hypertensive accompanying disease known from the case history, the need for rapid action and the fact that an abdominal revision could also be necessary, required that the operation be carried out under general anaesthesia. Intraoperatively, a wound secretion was seen in the vaginal setting in the vicinity of the suburethral colpotomy. Since this could be opened bluntly we decided upon a vaginal procedure. After performance of the revision operation without any complications, an initial postoperative anaemia (haemoglobin $5.23 \mathrm{mmol} / \mathrm{l}$ ) and reduced general condition necessitated administration of two erythrocyte concentrates to the patient. Under mobilisation, adequate increase of haemoglobin $(6.83 \mathrm{mmol} / \mathrm{l})$ and continuation of the antibiotic therapy as well as a marked reduction of the inflamma- 

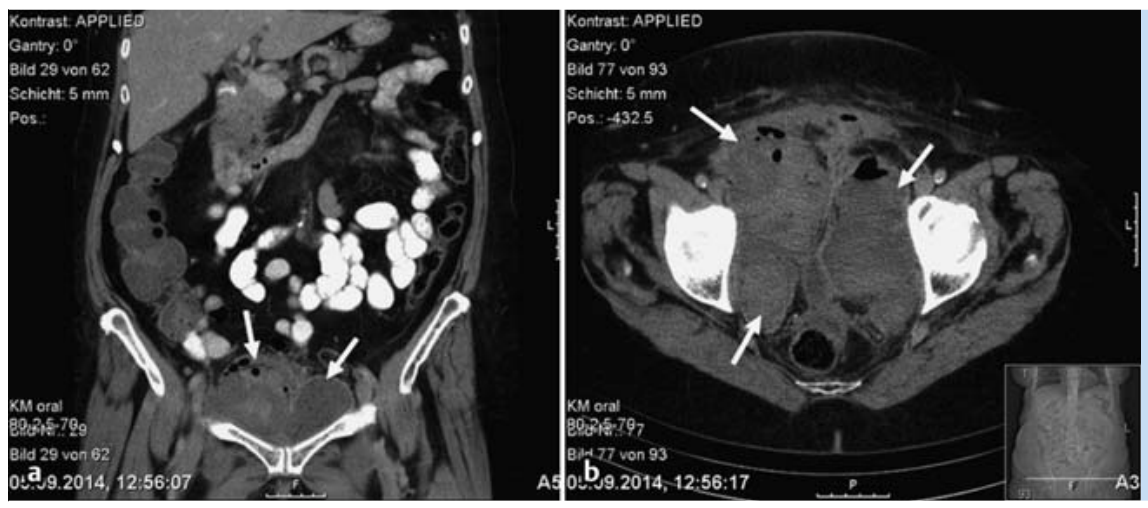

Fig. $\mathbf{2} \mathbf{a}$ and $\mathbf{b}$ Preoperative abdominal $\mathrm{CT}$ in the 2nd case with demonstration of a chambered, haemorrhagic and superinfected haematoma (ca. 600-700 ml) in the lesser pelvis without any evidence for a fistular connection to the bladder and intestine.

tory parameters, the patient recovered rapidly. In a control CT scan on the 2 nd postoperative day a small residual haematoma of $25 \mathrm{~mm}$ diameter was seen. Also the routine follow-up examination on the 2nd postoperative day did not show any remarkable findings apart from the remaining residual haematoma. The further postoperative course remained free of complications and the patient could be released home in good general condition and well-being on the 7th postoperative day. The first follow-up examination one week after release confirmed the unremarkable recovery process.

\section{Operative Procedure}

The vaginal haematoma removal was realised in both cases by opening the colpotomy and blunt preparation along the previously placed tape through to the retropubic space after the urogenital diaphragm had been punctured and opened sufficiently so that aspiration was possible. The aspiration is achieved under careful introduction of the aspirator along the previously inserted tape with the aspirator tip pointing medially in order to avoid injury to the obturator vessels as well as a reactivation of the old bleeding source. After several lavages, a suction drain is inserted and, in the first case, the colpotomy is closed. A vaginal tamponade and an indwelling catheter are left in place for $24 \mathrm{~h}$. The suction drainage is removed on the 2 nd postoperative day. In the second case ingrowth of the previously placed retropubic tape did not occur due to an inflammatory process so that it could be removed in toto by tension during the revision operation. Except for an adapting suture, the colpotomy is not closed in order to enable drainage of the wound secretions via two paravesically positioned drains. An indwelling catheter is left in place for $24 \mathrm{~h}$. The drainage is removed on the 3rd postoperative day.

\section{Discussion}

\section{$\nabla$}

The formation of a haematoma after insertion of retropubic tapes is a typical complication for which in the relevant literature both conservative and widely different surgical treatment options have been described. In the two cases reported here the retropubic haematomas could be successfully managed by a vaginal revision operation. The courses of the two patients differ with regard to the accompanying infection of the haematoma and the hypertensive accompanying disease in the second case. However, both cases demonstrated that the vaginal approach represents a gentle revision option for haematoma removal that, under certain circumstances, can also be performed under analgosedative local anaesthesia. In particular in the second case, a secondary wound healing would have been expected due to the obesity and the infected haematoma. The, in this case, unilaterally performed suburethral mesh removal could be topographically excluded as a cause for haematoma formation. A bilateral procedure would not have reduced the risk for formation of a retropubic haematoma.

Under consideration of the pain and circulatory stability of the patient, a haematoma size of $5-6 \mathrm{~cm}$ can be taken as a rough upper limit between a conservative wait-and-see procedure and a revision operation for haematoma removal, although one can find examples in the literature in which haematomas of up to $10 \mathrm{~cm}$ [5] have been treated conservatively. In the Austrian registry published in 2002 by Kölle et al. 2002 among 5578 cases of retropubic tape insertion there were 151 cases of bleeding complications and haematoma formation with a revision rate of $0.8 \%$. In 34 of 45 cases this was done via a laparotomy access. The revision operations were carried out in $30 \%$ of the cases within 24 hours, in $40 \%$ after $11-56$ days and the remaining $20 \%$ within $2-$ 11 days after insertion of the retropubic tapes [4]. Data collected by Flock et al. showed $4.1 \%$ haematoma formation after retropubic tape insertion [6,7]. Of 28 patients, 10 had to undergo a revision operation, since symptomatic haematomas with a volume of $>250 \mathrm{ml}$ were involved [7]. The patients suffered from abdominal pain, urge symptoms, dysuria and circulatory dysregulation. Patients with asymptomatic haematomas $<250 \mathrm{ml}$ can be treated by a conservative wait-and-see strategy [7]. After the first revision has been performed by a laparotomy, in subsequent procedures an endoscopic access is used [6,7]. The fact that, as a rule, no generally valid access route and time point for a revision operation can be given was considered as a self-limiting factor by Flock et al. so that these decisions have to be determined individually on a case to case basis [7].

Theoretically there are three possible scenarios for the surgical revision of a retropubic haematoma. The patient is hypovolemic and reports on pain in the immediate postoperative period; if this raises the suspicion of a retropubic haematoma/haemorrhage, it necessitates immediate action in general in the form of a subperitoneal revision operation by laparotomy to remove the haematoma. This procedure is especially required when, besides haematoma removal, the persistent, usually arterial bleeding site must be found and closed.

If, in the course of a postoperative routine examination during the hospital stay, sonography of the patient reveals a retropubic haematoma, this can, depending on its size, the patient's condition, and her circulatory stability under certain circumstances 
be removed under analgosedative local anaesthesia by the vaginal access in order to spare the patient from a more traumatic laparotomy procedure under a renewed general anaesthesia. The objective of the revision in such cases is the avoidance of a long and tedious convalescence with possibly functional bladder disorder, pain and risk of haematoma infection as well as adhesions in the paravesical space.

Since the vaginal access for removal of a retropubic haematoma represents a more gentle alternative, the vaginal revision should be preferred after a waiting time in cases where a retropubic haematoma is diagnosed in the immediate postoperative period, the patient's circulation is stable, and depending on the size of the haematoma in order to spare the patient from a laparotomy intervention. Clinical experience has shown that when waiting up to the third postoperative day a renewed bleeding into the haematoma cavity can be avoided by self-tamponade. If the revision is performed too soon it can reactivate the bleeding site.

\section{Conclusions}

$\nabla$

Depending on the urgency of a revision operation, the patient's circulatory stability and her pain perception, the vaginal access for revision of a haematoma after retropubic tape placement makes for a more atraumatic procedure in comparison to a laparotomy via a subperitoneal approach and, when the haematoma is well accessible, carries a lower risk of secondary wound healing. Under certain circumstances the patient can also be spared from a further general anaesthesia. Finally if sonography does not provide a sufficient clarification of the findings, further imaging procedures may be considered.

\section{Conflict of Interest}

$\nabla$

None.

\section{References}

1 Ulmsten U, Henriksson L, Johnson P et al. An ambulatory surgical procedure under local anesthesia for treatment of female urinary incontinence. Int Urogynecol J Pelvic Floor Dysfunct 1996; 7: 81-85

2 Reisenauer C, Muche-Borowski C, Anthuber C et al. Interdisciplinary S2e guideline for the diagnosis and treatment of stress urinary incontinence in women: short version - AWMF registry No. 015-005, July 2013. Geburtsh Frauenheilk 2013; 73: 899-903

3 Kuuva N, Nilsson CG. A nationwide analysis of complications associated with the tension-free vaginal tape (TVT) procedure. Acta Obstet Gynecol Scand 2002; 81: 72-77

4 Kölle D, Tamussino K, Hanzal E et al.; Austrian Urogynecology Working Group. Bleeding complications with the tension-free vaginal tape operation. Am J Obstet Gynecol 2005; 193: 2045-2049

5 Walters MD, Tulikangas PK, LaSala $C$ et al. Vascular injury during tension-free vaginal tape procedure for stress urinary incontinence. Obstet Gynecol 2001; 98: 957-959

6 Flock F, Reich A, Muche R et al. Hemorrhagic complications associated with Tension-free Vaginal Tape procedure. Obstet Gynecol 2004; 104: 989-994

7 Flock F, Kohorst F, Kreienberg $R$ et al. Retziusscopy: a minimal invasive technique for the treatment of retropubic hematomas after TVT procedure. Eur J Obstet Gynecol Reprod Biol 2011; 158: 101-103 